\title{
Hemoglobinuria, CTCAE 5.0
}

National Cancer Institute

\section{Source}

National Cancer Institute. Hemoglobinuria, CT CAE 5.0. NCI Thesaurus. Code C146768.

A disorder characterized by laboratory test results that indicate the presence of free hemoglobin in the urine. 